\title{
The home environment and asthma symptoms in childhood: two population based case-control studies 13 years apart
}

\author{
Barbara K Butland, David P Strachan, H Ross Anderson
}

\begin{abstract}
Background - Prevalence surveys of asthma and/or wheezing among all children aged between $7 \frac{1}{2}$ and $8 \frac{1}{2}$ attending state and private schools in the London Borough of Croydon were conducted in February 1978 and February 1991. Two population based case-control studies drawn from the survey responders were used to investigate the association between childhood wheeze and characteristics of the home environment and to assess whether changes in these characteristics between 1978 and 1991 may have contributed to an increase in the population prevalence of wheeze among school children.
\end{abstract}

Methods - Information on exposure to potential indoor environmental risk factors was obtained from parents by home interview and compared between cases - that is, children with frequent $(\geq 5)$ or infrequent (1-4) attacks of asthma or wheezing in the past 12 months - and controls, with adjustment for study. Changes in exposure over time were assessed by comparing control groups.

Results - Between 1978 and 1991 the population prevalence odds of wheeze increased by $20 \%$ (OR $1.20 ; 95 \%$ CI 1.04 to 1.39$)$. Change in parental smoking, gas cooking, pet ownership, and central heating did not appear to explain the rise. Use of nonfeather pillows was positively associated with childhood wheeze even after adjusting for other risk factors and after re-coding from non-feather to feather cases thought to have changed pillow in response to symptoms (OR 1.54 ; 95\% CI 1.13 to 2.10 ). The proportion of control children reportedly using non-feather pillows was $44 \%$ in 1978 and $67 \%$ in 1991 .

Conclusions - Increased use of non-feather pillows was the only domestic indoor exposure studied which appeared to explain a modest rise in prevalence of wheeze from 1978 to 1991 . Our analysis attempts to address behavioural change in response to the child's symptoms but an artifact arising from lifelong avoidance of feather bedding in atopic families cannot be entirely discounted.

(Thorax 1997;52:618-624)

Keywords: asthma, indoor environmental exposures, feather pillows.

In the London Borough of Croydon the 12 month period prevalence of wheeze among eight year old school children increased from $11.1 \%$ in 1978 to $12.9 \%$ in $1991 .^{1}$ Evidence from population surveys, ${ }^{1-6}$ GP consultation rates, ${ }^{7}$ and hospital admissions ${ }^{8}$ indicate that this was part of a national increase in the prevalence of childhood asthma throughout the 1970s and early 1980s. The reasons for the increase remain unclear. It has been suggested that changes in the indoor environment in terms of temperature, humidity, air pollutants, and allergen exposure may be partly responsible. ${ }^{69-11}$ A recent study of severe wheeze in Sheffield school children aged 11-16 suggested an increased risk associated with current exposure to non-feather pillows. ${ }^{1213}$

Between March 1978 and November 1979 and between March 1991 and January 1992 we conducted two population based case-control studies of eight year old Croydon school children which provided an opportunity to investigate the association between childhood wheeze and the indoor environment. We compared the control groups to investigate changes in indoor exposures over time and to assess the extent to which any changes might explain the observed increase in the prevalence of wheeze among Croydon children.

\section{Methods}

In February 1978 and again in February 1991 the same one page screening questionnaire was sent to the parents of all children aged between $7 \frac{1}{2}$ and $8 \frac{1}{2}$ attending state or private schools in the London Borough of Croydon. Response rates were $87 \%$ and $81 \%$, respectively. ${ }^{14}$

Children reported to have had five or more attacks of asthma or wheeziness in the past 12 months were targeted for home interview. Also targeted were samples of children reported to have had attacks less frequently (1-4) in the past 12 months, a 52\% sample in 1978 and a $100 \%$ sample in 1991 . Response rates were $95 \%$ and $81 \%$, respectively. ${ }^{14}$ Controls were selected from children reported never to have had asthma or wheeziness at screening. In 1991 an adjacent control was chosen for each case from the stack of screening questionnaires. As a result the distribution of controls by school differed from that in the population. In 1978 controls were selected at random. Home interviews were obtained with 94 out of 111 (85\%) controls in 1978 and 317 out of 377 $(84 \%)$ in 1991 . Further details on study design have been published elsewhere. ${ }^{14}$

The home interview obtained information on type of fuel for cooking, maternal and paternal 
smoking, type of heating in the living room and bedroom, whether or not the child had their own room, type of pillow and mattress, pet ownership, and socioeconomic measures including housing tenure and social class of the father.

Questions relating to parental smoking differed between studies with the 1991 questionnaire asking about cigarettes smoked in the home. Parents who smoke cigarettes but not in the home will therefore be coded differently in the two studies and for 1991 the number of cigarettes smoked per day will be biased downwards.

Parents were asked if they had ever got rid of a pet or decided not to have one because they thought that the study child was (or might be) sensitive to it. They were also questioned about special arrangements in the child's bedroom; however, the wording and position of this question differed between studies. In 1978 parents were asked "Have you done anything special about N's bedroom?" followed by questions on type of pillow, continental quilt, and mattress to act as a check. In 1991 they were asked "Have any other special arrangements been made in the room?" directly after the question "Do you use any kind of mattress cover?" but also after questions relating to type of pillow, bedding, and mattress. In both studies parents were asked to give details of any special arrangements.

ANALYSIS OF DATA

Multiple logistic regression models adjusting for study were fitted by $\mathrm{SAS}^{15}$ to investigate associations between attacks of asthma and wheezing and potential risk factors in the home environment. Due to the sampling scheme used in the 1978 study, results for frequent and infrequent attacks combined will be biased towards the more severe spectrum of disease. In order to assess independent effects, all potential risk factors that exhibited a significant association with either infrequent or frequent wheeze were entered into multifactorial models along with sex, social class, housing tenure, furry pets, central heating in the bedroom, and paternal smoking. Maternal smoking was entered as a three level factor to investigate dose response and the absence of a father figure as an extra social class category. An interaction term was included so that odds ratios for furry pets were estimated from a subset of the data - that is, children with no parental report of pet avoidance - while simultaneously estimating all other parameters in the same model from the full data. ${ }^{12}$ A similar technique could not be used for feather pillows as information on special arrangements in the bedroom was only collected from cases. Odds ratios for feather pillows, adjusted for study and other potential risk factors, were therefore obtained by refitting models to a restricted data set - that is, children with no report of special arrangements in the bedroom.

Methods similar to those described by Breslow and Day ${ }^{16}$ were used to assess the extent to which changes in the distributions of risk factors over time (1978-91) could explain the small increase in the population prevalence odds of asthma and wheezing attacks between the two studies. Calculations were based on the assumption that the underlying associations between risk factors and wheeze were the same in the 1978 and 1991 populations.

Mantel-Haenszel statistics calculated by SAS $^{15}$ from three-way tables involving an indicator for study were used to investigate associations between potential risk factors and wheeze frequency. The extent of any bias arising from the method of control selection used in 1991 was investigated by fitting multiple logistic regression models for all wheeze that used a single multilevel factor to represent both study and 1991 school. The resulting odds ratios obtained were compared with the results of the main analysis.

\section{Results}

SCREENING DATA

The 12 month period prevalence of wheezing attacks increased from $11.1 \%$ to $12.9 \%$ (table 1), a moderate but significant increase of $16 \%$ (95\% CI $2 \%$ to $32 \%) .{ }^{14}$ The increase was mainly due to a change in the prevalence of infrequent symptoms which rose from $8.4 \%$ to $10.1 \%{ }^{114}$ There was little change in the prevalence of frequent wheeze $(2.5 \%$ to $2.6 \%$, respectively). ${ }^{114}$ The ratio of current wheezers to never wheezers (population prevalence odds) increased by $20 \%$ between 1978 and 1991 .

\section{HOME INTERVIEW DATA}

Cases and selected controls for whom a false positive or a false negative response on the

Table 1 Prevalence odds ratios for current and past wheeze comparing the two screening surveys of eight year old Croydon school children conducted in 1991 and 1978

\begin{tabular}{|c|c|c|c|c|}
\hline Wheezing or asthma & $\begin{array}{l}1978 \\
n(\%)\end{array}$ & $\begin{array}{l}1991 \\
n(\%)\end{array}$ & $\begin{array}{l}\text { Prevalence ratio } \\
1991 \text { versus } 1978 \\
(95 \% \text { CI) }\end{array}$ & $\begin{array}{l}\text { Odds ratio } \\
1991 \text { versus } 1978 \\
(95 \% \text { CI })\end{array}$ \\
\hline $1-4$ attacks in the past 12 months & $349(8.43)$ & $310(10.12)$ & \multirow{5}{*}{$\begin{array}{l}1.20^{*} \\
(1.04 \text { to } 1.39) \\
1.04 \\
(0.78 \text { to } 1.38) \\
1.16^{*} \\
(1.02 \text { to } 1.32) \\
1.15 \\
(0.98 \text { to } 1.35)\end{array}$} & \multirow{5}{*}{$\begin{array}{l}1.24^{* *} \\
(1.05 \text { to } 1.47) \\
1.07 \\
(0.79 \text { to } 1.46) \\
1.20^{*} \\
(1.04 \text { to } 1.39) \\
1.19 \\
(0.99 \text { to } 1.43)\end{array}$} \\
\hline Five or more attacks in the past 12 months & $103(2.48)$ & $79(2.57)$ & & \\
\hline Attacks in the past 12 months $\dagger$ & $459(11.07)$ & $395(12.87)$ & & \\
\hline $\begin{array}{l}\text { Previous attacks but not in the past } 12 \\
\text { months }\end{array}$ & $289(6.97)$ & $246(8.01)$ & & \\
\hline $\begin{array}{l}\text { Never (controls) } \\
\text { Total }\end{array}$ & $\begin{array}{l}3399(81.96) \\
4147\end{array}$ & $\begin{array}{l}2429(79.12) \\
3070\end{array}$ & & \\
\hline
\end{tabular}


Table 2 Associations between the parental reporting of frequent and infrequent wheeze in the past 12 months and potential risk factors in case-control studies, 1978 and 1991

\begin{tabular}{|c|c|c|c|c|c|c|c|c|}
\hline \multirow[t]{2}{*}{ Risk factor } & \multicolumn{3}{|c|}{ Croydon (1978) } & \multicolumn{3}{|c|}{ Croydon (1991) } & \multirow{2}{*}{$\begin{array}{l}\text { Odds ratio }(95 \% \text { CI) } \\
\text { for infrequent wheeze } \ddagger\end{array}$} & \multirow{2}{*}{$\begin{array}{l}\text { Odds ratio }(95 \% \mathrm{CI}) \\
\text { for frequent wheeze }\end{array}$} \\
\hline & $\begin{array}{l}\text { Control } \\
(n=92) \\
(\%)\end{array}$ & $\begin{array}{l}\text { Infrequent } \\
\text { wheeze } \\
(n=173) \\
(\%)\end{array}$ & $\begin{array}{l}\text { Frequent } \\
\text { wheeze } \\
(n=94) \\
(\%)\end{array}$ & $\begin{array}{l}\text { Control } \\
(n=291) \\
(\%)\end{array}$ & $\begin{array}{l}\text { Infrequent } \\
\text { wheeze } \\
(n=235) \\
(\%)\end{array}$ & $\begin{array}{l}\text { Frequent } \\
\text { wheeze } \\
(n=64) \\
(\%)\end{array}$ & & \\
\hline \multicolumn{9}{|l|}{ Indoor pollution } \\
\hline Gas cooking & 75.0 & 81.9 & 80.9 & 75.3 & 82.1 & 76.6 & $1.50(1.06 \text { to } 2.13)^{*}$ & $1.22(0.76$ to 1.96$)$ \\
\hline Mother smokes\# & 36.7 & 40.2 & 43.0 & 24.8 & 30.6 & 37.5 & $1.27(0.93$ to 1.74$)$ & $1.55(1.02$ to 2.34$) *$ \\
\hline Father smokes\#† & 46.7 & 45.8 & 45.2 & 24.4 & 26.1 & 28.1 & $1.04(0.76$ to 1.43$)$ & $1.06(0.69$ to 1.62$)$ \\
\hline \multicolumn{9}{|l|}{ Social and economic variables } \\
\hline Male & 46.7 & 59.5 & 47.9 & 51.6 & 54.9 & 54.7 & $1.29(0.97$ to 1.72$)$ & $1.09(0.74$ to 1.62$)$ \\
\hline $\begin{array}{l}\text { Father employed in non-manual } \\
\text { occupation }\end{array}$ & 45.3 & 43.9 & 51.2 & 59.7 & 61.1 & 54.7 & $1.02(0.75$ to 1.39$)$ & $1.01(0.66$ to 1.55$)$ \\
\hline No father figure & 6.5 & 8.7 & 10.6 & 9.3 & 15.0 & 17.2 & $1.63(1.02 \text { to } 2.62)^{*}$ & $1.91(1.03 \text { to } 3.57)^{*}$ \\
\hline Parents own home & 58.7 & 61.8 & 61.7 & 81.1 & 76.2 & 70.3 & $0.88(0.64$ to 1.22$)$ & $0.81(0.52$ to 1.25$)$ \\
\hline \multicolumn{9}{|l|}{ Housing variables } \\
\hline Central heating in the lounge & 56.5 & 47.7 & 52.1 & 83.5 & 79.9 & 82.8 & $0.75(0.53$ to 1.05$)$ & $0.88(0.56$ to 1.38$)$ \\
\hline Central heating in the bedroom & 50.0 & 44.2 & 44.7 & 80.8 & 79.1 & 81.3 & $0.86(0.62$ to 1.19$)$ & $0.90(0.58$ to 1.39$)$ \\
\hline Child has own bedroom & 55.4 & 50.6 & 59.6 & 52.6 & 52.8 & 53.1 & $0.95(0.71$ to 1.26$)$ & $1.09(0.74$ to 1.63$)$ \\
\hline \multicolumn{9}{|c|}{ Possible/potential sources of airborne allergens } \\
\hline Feather pillow & 55.6 & 32.0 & 18.5 & 31.1 & 21.6 & 10.9 & $0.51(0.37 \text { to } 0.70)^{* * *}$ & $0.21(0.12 \text { to } 0.36)^{* * *}$ \\
\hline Sprung mattress & 83.1 & 83.2 & 90.0 & 90.5 & 88.7 & 85.7 & $0.89(0.57$ to 1.39$)$ & $1.03(0.55$ to 1.96$)$ \\
\hline Furry pets & 57.6 & 59.5 & 62.8 & 51.5 & 50.2 & 54.7 & $0.99(0.74$ to 1.31$)$ & $1.18(0.79$ to 1.76$)$ \\
\hline
\end{tabular}

$* \mathrm{p}<0.05 ; * * \mathrm{p}<0.01 ; * * \mathrm{p}<0.001$.

t Coded as non-smoker if no father figure.

$¥ 1978$ and 1991 data combined, odds ratio adjusted for study.

\# Smoking = cigarettes, cigars and/or pipe.

screening questionnaire was suspected were excluded from analyses, with the additional exclusion of 10 cases in 1991 who were interviewed as former rather than current wheezers, three cases in 1991 for whom frequency of attack was unknown, and one case in 1978 whose interview was "unusable". ${ }^{14}$ Analyses were therefore based on 94 and 64 frequent wheezers, 173 and 235 infrequent wheezers, and 92 and 291 controls from the 1978 and 1991 studies, respectively.

Having adjusted only for study, the prevalence of childhood wheezing illness was positively associated with gas cooking, maternal smoking, and the absence of a father figure and negatively associated with the use of feather pillows (table 2). There were no significant associations with furry pets or central heating. Odds ratios for maternal smoking and the absence of a father figure appeared to increase across groups (control, infrequent, frequent wheeze) and those for feather pillows appeared to decrease $(\mathrm{p}=0.025, \mathrm{p}=0.016$ and $\mathrm{p}$ $<0.001$, respectively).

When we looked at the number of cigarettes smoked per day by the mother there was no evidence of a dose response relationship. With both frequent and infrequent wheeze the odds ratio for mild smokers (1-9 cigarettes per day versus none) was larger than the odds ratio for moderate/heavy smokers ( $\geq 10$ cigarettes per day versus none). The same pattern was observed in the 1978 data and the 1991 data although it was more marked in the latter.

PATTERNS OF ALLERGEN AVOIDANCE

One possible explanation for the strong negative association with feather pillows is that parents changed to non-feather pillows in response to their child's symptoms. Avoidance of pets due to symptoms may also explain the failure to detect any increase in risk associated with current pet ownership.
In both studies about $30 \%$ of frequent wheezers and about $15 \%$ of infrequent wheezers had a report of pet avoidance compared with $7 \%$ of controls in the 1978 study and $2 \%$ of controls in the 1991 study. Special arrangements in the bedroom were reported for about $20 \%$ of infrequent wheezers, $55 \%$ of frequent wheezers in 1978, and $34 \%$ of frequent wheezers in 1991. Among parents of children with frequent wheeze, in $197823 \%$ specified changing pillows, avoiding feathers or using non-feather pillows compared with only $3 \%$ in 1991 (table 3). For infrequent wheeze the difference was less marked ( $7 \%$ versus $3 \%$ ). A similar pattern was observed for parents specifying a change of bedding or use of nonfeather/non-wool bedding $-15 \%$ versus $2 \%$ for those with frequent wheeze and $4 \%$ versus $3 \%$ for infrequent wheezers. This may indicate a certain degree of under reporting in the 1991 study due to the wording and positioning of the question on special arrangements.

\section{Adjusting for patterns of avoidance}

When children from households with a report of pet avoidance were excluded from the analysis a positive but non-significant association with furry pets emerged which was larger for frequent than infrequent wheeze (table 4). Excluding subjects with a report of special arrangements in the bedroom failed to remove the significant reduction in the odds of wheeze associated with feather pillows.

When, instead of excluding children, those with a report of special arrangements that specifically mentioned changing pillows, using non-feather pillows, feather avoidance, changing bedding, or non-feather/non-wool bedding were re-coded from non-feather to feather, the odds ratios for feather pillows increased in magnitude to 0.54 (95\% CI 0.34 to 0.84 ) for frequent wheeze and 0.66 (95\% CI 0.49 to 0.90 ) for infrequent wheeze but remained stat- 
Table 3 Number (\%) of cases and controls reporting special arrangements in the child's bedroom

\begin{tabular}{|c|c|c|c|c|c|c|c|}
\hline \multirow[t]{3}{*}{ Current pillow } & \multirow[t]{3}{*}{ Change of pillow* } & \multicolumn{3}{|c|}{ Croydon (1978) } & \multicolumn{3}{|c|}{ Croydon (1991) } \\
\hline & & \multirow{2}{*}{$\begin{array}{l}\text { Control } \\
(n=90)\end{array}$} & \multicolumn{2}{|l|}{ Case } & \multirow{2}{*}{$\begin{array}{l}\text { Control } \\
(n=289)\end{array}$} & \multicolumn{2}{|l|}{ Case } \\
\hline & & & $\begin{array}{l}<5 \text { attacks } \\
(n=169)\end{array}$ & $\begin{array}{l}\geq 5 \\
\text { attacks } \\
(n=92)\end{array}$ & & $\begin{array}{l}<5 \text { attacks } \\
(n=232)\end{array}$ & $\underset{(n=64)}{\geq 5 \text { attacks }}$ \\
\hline \multirow[t]{4}{*}{ Feather } & Yes & & $0(0.0)$ & $0(0.0)$ & & $0(0.0)$ & $0(0.0)$ \\
\hline & Not & $50(55.6)$ & $47(27.8)$ & $14(15.2)$ & $90(31.1)$ & $46(19.8)$ & $5(7.8)$ \\
\hline & No but change of bedding $\dagger$ & & $0(0.0)$ & $0(0.0)$ & & $0(0.0)$ & $0(0.0)$ \\
\hline & No but other special arrangements in the child's bedroom & & $7(4.1)$ & $3(3.3)$ & & $4(1.7)$ & $2(3.1)$ \\
\hline \multirow[t]{4}{*}{ Non-feather } & Yes & & $12(7.1)$ & $21(22.8)$ & & $8(3.4)$ & $2(3.1)$ \\
\hline & No $\ddagger$ & $40(44.4)$ & $83(49.1)$ & $28(30.4)$ & $199(68.9)$ & $139(59.9)$ & $37(57.8)$ \\
\hline & No but change of beddingt & & $1(0.6)$ & $5(5.4)$ & & $1(0.4)$ & $0(0.0)$ \\
\hline & No but other special arrangements in the child's bedroom & & $19(11.2)$ & $21(22.8)$ & & $34(14.7)$ & $18(28.1)$ \\
\hline
\end{tabular}

* Special arrangements reported and specified as changing pillows, using non-feather pillows, or avoiding feathers.

† Special arrangements reported and specified as change of bedding or use of non-feather/non-wool bedding.

† $\$$ For controls "no" is taken to mean no information.

Table 4 Association of feather pillows and furry pets with the 12 month period prevalence of wheeze after excluding subjects who may have changed their behaviour in response to symptoms

\begin{tabular}{|c|c|c|c|c|c|c|c|c|c|}
\hline & & \multicolumn{3}{|c|}{ Croydon (1978) } & \multicolumn{3}{|c|}{ Croydon (1991) } & \multirow{2}{*}{$\begin{array}{l}\text { Odds ratio (95\% } \\
\text { CI) infrequent } \\
\text { wheeze versus } \\
\text { control }\end{array}$} & \multirow{2}{*}{$\begin{array}{l}\text { Odds ratio (95\% } \\
\text { CI) frequent } \\
\text { wheeze versus } \\
\text { control }\end{array}$} \\
\hline & & Control & $\begin{array}{l}\text { Infrequent } \\
\text { wheeze }\end{array}$ & $\begin{array}{l}\text { Frequent } \\
\text { wheeze }\end{array}$ & Control & $\begin{array}{l}\text { Infrequent } \\
\text { wheeze }\end{array}$ & $\begin{array}{l}\text { Frequent } \\
\text { wheeze }\end{array}$ & & \\
\hline \multicolumn{10}{|l|}{ Furry pets } \\
\hline \multirow[t]{2}{*}{ All children } & Total & 92 & 173 & 94 & 291 & 235 & 64 & 0.99 & 1.18 \\
\hline & $\%$ with furry pets & 57.6 & 59.5 & 62.8 & 51.5 & 50.2 & 54.7 & (0.74 to 1.31$)$ & (0.79 to 1.76$)$ \\
\hline \multirow{2}{*}{$\begin{array}{l}\text { No parental report of } \\
\text { pet avoidance }\end{array}$} & Total & 86 & 146 & 65 & 284 & 199 & 45 & 1.17 & 1.51 \\
\hline & $\%$ with furry pets & 57.0 & 63.7 & 66.2 & 51.8 & 54.3 & 62.2 & (0.86 to 1.58$)$ & (0.95 to 2.40$)$ \\
\hline \multicolumn{10}{|l|}{ Feather pillow } \\
\hline \multirow[t]{2}{*}{ All children } & Total & 90 & 169 & 92 & 289 & 232 & 64 & $0.51 * * *$ & $0.21 * * *$ \\
\hline & $\%$ with feather pillow & 55.6 & 32.0 & 18.5 & 31.1 & 21.6 & 10.9 & $(0.37$ to 0.70$)$ & $(0.12$ to 0.36$)$ \\
\hline \multirow{2}{*}{$\begin{array}{l}\text { No parental report of special } \\
\text { arrangements in the child's } \\
\text { bedroom }\end{array}$} & Total & 90 & 130 & 42 & 289 & 185 & 42 & $0.61^{* *}$ & $0.36 * * *$ \\
\hline & $\%$ with feather pillow & 55.6 & 36.2 & 33.3 & 31.1 & 24.9 & 11.9 & (0.44 to 0.85$)$ & $(0.20$ to 0.64$)$ \\
\hline
\end{tabular}

$* \mathrm{p}<0.05, * * \mathrm{p}<0.01, * * * \mathrm{p}<0.001$

istically significant. The new variable produced by re-coding was used to represent past pillow use.

Changes in the behaviour of parents in response to symptoms are not the only source of bias. Parental behaviour may have been influenced by their own history of atopic disease even before symptoms developed in their child. When children with a parental history of asthma, wheezing, eczema or hay fever were excluded from the analysis, the association between frequent wheeze and furry pets reached statistical significance $(\mathrm{OR}=2.48 ; 95 \% \mathrm{CI}$ 1.15 to 5.39). A smaller non-significant rise was recorded for infrequent wheeze $(\mathrm{OR}=$ $1.13 ; 95 \%$ CI 0.69 to 1.83 ). With respect to feather pillows, the negative association with both infrequent and frequent wheeze persisted $(\mathrm{OR}=0.61 ; 95 \%$ CI 0.35 to 1.05 and $\mathrm{OR}=$ 0.23 ; $95 \%$ CI 0.09 to 0.58 , respectively) although, due to the small numbers, the association with infrequent wheeze was no longer significant.

\section{INDEPENDENT EFFECTS}

After adjustment for other variables, maternal smoking was only significantly associated with frequent wheeze when expressed as a three rather than a two level factor. However, there was no graded dose response with the highest odds ratios being recorded for mild smokers rather than moderate/heavy smokers (table 5).

With respect to gas cooking, the effect of adjustment was to reduce the odds ratio for infrequent wheeze from 1.50 to 1.34 with a subsequent loss of statistical significance (table 5). The association with lack of a father figure also lost significance. When models were refitted, replacing social class with the binary indicator father figure present versus absent, the adjusted all wheeze odds ratio was 1.62 with $95 \%$ confidence interval 0.96 to 2.75 .

The inverse association between childhood wheeze and feather pillows persisted and remained statistically significant. The use of feather pillows appeared to be associated with a reduction in the odds of infrequent wheeze of $36 \%(\mathrm{OR}=0.64 ; 95 \%$ CI 0.45 to 0.90$)$ and a reduction in the odds of frequent wheeze of $61 \%(\mathrm{OR}=0.39 ; 95 \% \mathrm{CI} 0.21$ to 0.76$)$ (table 5). When, instead of excluding subjects, we analysed past rather than current pillow use, the odds ratio for feather pillows increased in magnitude to 0.53 (95\% CI 0.32 to 0.87 ) for frequent wheeze, to 0.68 (95\% CI 0.49 to $0.94)$ for infrequent wheeze, and to $0.65(95 \%$ CI 0.48 to 0.89 ) for all wheeze combined, but remained statistically significant. However, when the analysis of past pillow use was restricted to children with no reported parental history of asthma, wheezing, eczema or hay fever, the odds ratio for all wheeze got even closer to 1 (OR $=0.74 ; 95 \%$ CI 0.43 to 1.27 ) and lost statistical significance.

Odds ratios for all wheeze by gas cooking, central heating, paternal smoking, and furry pets differed little from those already quoted in table 5 when, in addition to study and risk factors, we adjusted for school in the 1991 data. The new school adjusted odds ratios for absence of a father figure, feather pillows (based 
Table 5 Mutually adjusted odds ratios $\dagger$ for infrequent wheeze, frequent wheeze and all wheeze

\begin{tabular}{|c|c|c|c|}
\hline \multirow[t]{2}{*}{ Risk factor } & \multicolumn{3}{|c|}{ Mutually adjusted odds ratio $\dagger(95 \% \mathrm{CI})$} \\
\hline & Infrequent wheeze & Frequent wheeze & All wheeze $\ddagger$ \\
\hline \multicolumn{4}{|l|}{ Indoor pollution } \\
\hline \multicolumn{4}{|l|}{ Gas cooking } \\
\hline No & Baseline & Baseline & Baseline \\
\hline Yes & $1.34(0.93$ to 1.95$)$ & $1.19(0.68$ to 2.07$)$ & $1.34(0.95$ to 1.89$)$ \\
\hline \multicolumn{4}{|l|}{ Maternal smoking } \\
\hline No & Baseline & Baseline* & Baseline \\
\hline $1-9$ cigs per day & $1.52(0.84$ to 2.78$)$ & $2.63(1.22$ to 5.66$)$ & $1.77(1.01$ to 3.10$)$ \\
\hline$\geq 10$ cigs per day & $1.02(0.68$ to 1.53$)$ & $1.16(0.63$ to 2.15$)$ & $0.99(0.67$ to 1.47$)$ \\
\hline \multicolumn{4}{|l|}{ Paternal smoking } \\
\hline No & Baseline & Baseline & Baseline \\
\hline Yes & $1.03(0.71$ to 1.50$)$ & $1.04(0.59$ to 1.83$)$ & $1.04(0.73$ to 1.49$)$ \\
\hline \multicolumn{4}{|l|}{ Housing variables } \\
\hline \multicolumn{4}{|c|}{ Central heating in child's bedroom } \\
\hline No & Baseline & Baseline & Baseline \\
\hline Yes & $0.87(0.59$ to 1.29$)$ & $1.16(0.63$ to 2.14$)$ & $0.94(0.64$ to 1.37$)$ \\
\hline \multicolumn{4}{|c|}{ Sources of airborne allergens } \\
\hline \multicolumn{4}{|c|}{ Feather pillow $\$$} \\
\hline No & Baseline* & Baseline** & Baseline** \\
\hline Yes & $0.64(0.45$ to 0.90$)$ & $0.39(0.21$ to 0.76$)$ & $0.60(0.43$ to 0.84$)$ \\
\hline \multicolumn{4}{|l|}{ Furry pets } \\
\hline No & Baseline & Baseline & Baseline \\
\hline Yes & $1.19(0.86$ to 1.65$)$ & $1.42(0.85$ to 2.36$)$ & $1.26(0.93$ to 1.71$)$ \\
\hline
\end{tabular}

on current pillow use and restricted to children with no report of special arrangements), mild maternal smoking, and moderate/heavy maternal smoking were $1.46(95 \%$ CI 0.82 to $2.58), 0.51(95 \%$ CI 0.35 to 0.74$), 1.86(95 \%$ CI 1.01 to 3.42$)$ and 1.00 (95\% CI 0.65 to 1.53), respectively. When, instead of school, we adjusted for interviewer in the 1991 data, using similar methodology the new odds ratios for maternal smoking were 1.67 (95\% CI 0.95 to 2.94 ) for mild smokers and 1.02 (95\% CI 0.69 to 1.51 ) for moderate/heavy smokers.

CHANGES IN RISK FACTORS BETWEEN 1978 AND 1991

The control groups were compared in an attempt to investigate changes in potential risk factors over time. In the interests of comparability, percentages in 1991 were weighted according to the distribution of schools among all children reported never to have had asthma or wheeziness on the screening questionnaire (although these weighted percentages differed little from the unweighted figures presented in table 2). The comparison of controls suggested increases in the proportion of home owners $(59 \%$ to $80 \%)$, the proportion living in accommodation with central heating in the bedroom $(50 \%$ to $79 \%)$ and in the living room ( $57 \%$ to $81 \%$ ), and the proportion of children using non-feather pillows ( $44 \%$ to $67 \%$ ). The proportion of mothers who smoked appeared to decrease ( $37 \%$ to $25 \%$ ) as did the proportion of fathers who smoked ( $47 \%$ to $25 \%$ ), although it should be remembered that smoking questions were not strictly comparable between the two studies. The distribution of social class also appeared to differ between studies with $45 \%$ of control children in 1978 having fathers in non-manual occupations compared with $57 \%$ in 1991 . There appeared to be little change in the proportion using gas for cooking $(75 \%$ versus $77 \%$ ) or the proportion owning furry pets ( $58 \%$ versus $52 \%$ ).
Using the estimated odds ratio for all wheeze by past pillow use $(0.65$, feather versus nonfeather), a rise in the use of non-feather pillows from $44 \%$ to $67 \%$ would be large enough to explain $57 \%$ (95\% CI $18 \%$ to $96 \%$ ) of the $20 \%$ increase in the population prevalence odds of wheeze. A small rise in the use of gas for cooking from $75 \%$ to $77 \%$ would only be large enough to explain $4 \%$ of the $20 \%$ increase. Changes in the distributions of other potential risk factors including central heating, maternal smoking, paternal smoking, and furry pet ownership were conducive to a decrease in the population prevalence odds of wheeze rather than an increase. Taken together, the risk factors investigated in the multifactorial analysis (including non-feather pillows) appeared to explain $52 \%$ of the increase in the population prevalence odds of wheeze.

\section{Discussion}

Some authors commenting on trends in the prevalence of asthma have suggested that changes in exposures within the indoor environment may have been responsible. ${ }^{9-11}$ More specifically, some have suggested that changes in the way in which we heat and insulate our homes have provided a warmer more humid environment that might favour the growth of the house dust mite ${ }^{6}{ }^{6}$ However, the only study of dust mites conducted in English homes at two time points (1979 and 1989) failed to demonstrate any change in the reservoir levels of dust mite antigen. ${ }^{10}$ In our study we looked at the possible role of central heating. Although we found evidence of a large increase in the proportion of children with central heating in the bedroom between 1978 and 1991, there was no evidence to suggest that central heating was positively associated with wheeze, with a mutually adjusted odds ratio of less than 1 .

Use of gas for cooking is an important source of personal exposure to nitrogen dioxide, an irritant gas which might increase the risk of 
symptoms by toxic irritation or enhancement of the effects of infections or allergens. ${ }^{1718}$ The average additional exposure associated with a gas cooker is approximately $30 \mu \mathrm{g} / \mathrm{m}^{3}$ (16 ppb at $\left.20^{\circ} \mathrm{C}, 1013 \mathrm{mb}\right)^{17}$ compared with the average outdoor exposure in London of around 37 ppb. ${ }^{19}$ The mutually adjusted odds ratio associating wheeze with gas cooking in Croydon was small and non-significant although comparable to the results of a recent meta-analysis which suggested a $20 \%$ increase in the odds of respiratory symptoms prevalence with a $95 \%$ confidence interval of $10 \%$ to $30 \% .{ }^{17}$ However, the proportion of parents using gas for cooking appeared little changed between 1978 and 1991, hence gas cooking does not appear to explain the $20 \%$ increase in the population prevalence odds of wheeze observed between the two Croydon screening surveys.

A positive association between wheezing illness and maternal smoking has been reported by several studies, ${ }^{20-26}$ although there is debate as to whether it is smoking during pregnancy, during the child's first year of life, or current smoking by the mother that is important..$^{22325}$ In Croydon the association with maternal smoking as a two level factor lost statistical significance after adjustment for potential confounders and there was no suggestion of a dose response relationship. There was, however, some indication of an increased risk associated with mild smoking (1-9 cigarettes per day). This pattern, which was particularly marked in the 1991 study, might suggest that mothers whose children develop symptoms reduce the amount they smoke or reduce the amount they smoke in the home rather than give up.

The apparent decrease over time in the proportion of mothers who smoke may be an artifact of using different smoking questions. However, for the direction of the observed difference to be reversed we would need to assume that approximately $12 \%$ of mothers in the 1991 control group were current cigarette smokers who did not smoke in the home. The only available information comes from 174 control questionnaires completed in 1991 by two researchers who routinely noted down whether parents currently smoked as well as the number of cigarettes they smoked in the home. Of these 174 controls, four mothers smoked but not in the home, and five mothers who did not smoke in the home had missing information on smoking in general, a total of $5 \%(9 / 174)$. Thus, a change in the prevalence of maternal smoking between studies does not appear to explain the $20 \%$ increase in the population prevalence odds of wheeze. There was no evidence of an association between wheezing illness and paternal smoking habit.

It is unlikely that outdoor sulphur dioxide or particles (measured as black smoke) contributed to the $20 \%$ increase in the population prevalence odds of wheeze as levels of these two pollutants recorded at a local monitor in Croydon fell from $87.2 \mu \mathrm{g} / \mathrm{m}^{3}$ and $20.7 \mu \mathrm{g} / \mathrm{m}^{3}$ in 1978 to $19.5 \mu \mathrm{g} / \mathrm{m}^{3}$ and $13.3 \mu \mathrm{g} / \mathrm{m}^{3}$ in 1991 (Source: AEA Technology). Comparable information for ozone and nitrogen dioxide was not available, but in Central London annual mean concentrations of ozone decreased between 1978 and 1988 and annual mean concentrations of nitrogen dioxide were relatively stable over the same period. ${ }^{27}$ At a national level, a review of evidence in $1995^{27}$ concluded that changes in the scale and nature of air pollution were unlikely to have been responsible for the increase in asthma that has taken place over recent decades in the UK.

The higher odds of wheeze among children with no father figure lost significance after adjustment for confounders and the odds ratio decreased further in magnitude after additional adjustment for school in the 1991 data. "No father figure" was not a variable that we set out to examine and the discovery of an association in our initial analysis (table 2) was unexpected. However, other studies have reported elevated risks for children from one parent families ${ }^{24}$ and for children of unemployed parents or those of lowest socioeconomic status. ${ }^{2829}$

Few epidemiological studies have reported a positive association between pet ownership and wheezing illness. ${ }^{202130-32}$ However, evidence that exposure to pet dander increases the risk of allergic sensitisation has been provided by several clinical investigations. ${ }^{3133-35}$ A possible reason for this apparent contradiction is the avoidance of pets by the parents of children with symptoms. ${ }^{12130}$ The findings of the Croydon surveys, with odds ratios for furry pet ownership increasing in magnitude after excluding children with a parental report of pet avoidance, clearly lend weight to this interpretation. However, between 1978 and 1991 the proportion of parents owning furry pets appears if anything to have decreased so furry pet ownership does not appear to explain the $20 \%$ increase in the population prevalence odds of wheeze.

One factor for which trends in exposure were conducive to an increase in the prevalence of wheeze was type of pillow. The paradoxical inverse association of wheeze with feather pillows was also reported in a recent study of 11-16 year old Sheffield school children. ${ }^{12}$ In both Sheffield and Croydon the association persisted even after the exclusion of children with a report of special arrangements in the bedroom and after adjustment for other potential confounding factors. The resulting odds ratios were also similar $(0.36 ; 95 \%$ CI 0.24 to 0.53 for severe and/or frequent wheeze in Sheffield, $0.40 ; 95 \%$ CI 0.21 to 0.76 for frequent wheeze in Croydon). ${ }^{12}$

In the Sheffield study no detailed information was available about change in pillow use as a result of the child's asthma. However, in Croydon we were able to take account of feather avoidance more specifically and the inverse association persisted, although there was some concern that change of pillow may have gone under-reported in the 1991 study. This form of analysis does not take account of the possibility that atopic families tend to avoid feather bedding from the time their children are born, thus introducing an artifactual association of allergic disease and non-feather bedding. Restriction of the analysis to children without a family history of allergic disease, which partly ad- 
dresses this concern, saw the association lose significance, although the direction was unchanged.

We were unable to assess the possible biasing effects of differences in response rates between studies and between cases and controls. However, bias due to the sampling of controls in the 1991 study appeared from our school adjusted analysis to have inflated (moving it closer to 1) rather than deflated the odds ratio for feather pillows.

Our findings relate to trends in wheezing and environmental exposures in one London borough and their broader relevance to the increase in childhood asthma that took place throughout Britain in the 1970s and early 1980s is difficult to assess. The causal interpretation of a positive association between childhood wheezing and the use of non-feather pillows is uncertain ${ }^{136}$ and further toxicological and epidemiological studies are required. The possibility that changes in behaviour in response to atopic disease and lifelong avoidance of feather bedding in atopic families have combined to produce a spurious association cannot be entirely discounted.

The 1978 study was funded by South West Thames Regional Health Authority and funds for the second study in 1991 were provided by the National Asthma Campaign. The authors would like to thank Katie Paine, Susan Wilkinson and the late Francis like to thank Katie Paine, Susan Wilkinson and the late Francis
Coton for conducting home interviews in 1991. We would also Coton for conducting home interviews in 1991. We would also
like to thank the Education and Health Authorities of Croydon for their support, the individual schools for their cooperation, and all the children and parents who took part and made both studies possible.

1 Strachan DP, Anderson HR. Trends in hospital admission rates for asthma in children. BMF 1992;304:819-20.

2 Hill R, Williams J, Tattersfield A, Britton J. Change in use of asthma as a diagnostic label for wheezing illness in of asthma as a diagnostic label for
schoolchildren. BMF 1989;299:898.

3 Burney PGJ, Chinn S, Rona RJ. Has the prevalence of asthma increased in children? Evidence from the national study of health and growth 1973-1986. BMF 1990;300: $1306-10$.

4 Burr ML, Butland BK, King S, Vaughan-Williams E. Changes in asthma prevalence:two surveys 15 years apart. Arch Dis Child 1989;64:1452-6.

5 Whincup PH, Cook DG, Strachan DP, Papacosta O. Time trends in respiratory symptoms in childhood over a 24 year period. Arch Dis Child 1993;68:729-34.

6 Ninan TK, Russell G. Respiratory symptoms and atopy in Aberdeen school children:evidence from two surveys 25 years apart. BMF 1992:304:873-5.

7 Fleming DM, Crombie DL. Prevalence of asthma and hay fever in England and Wales. BMF 1987;294:279-83.

8 Lung and Asthma Information Agency. Trends in hospital admissions for asthma. Factsheet 95/1. London: St George's
Hospital Medical School Department of Public Health Sciences, 1995 .

9 Omran M, Russell G. Continuing increase in respiratory symptoms and atopy in Aberdeen schoolchildren. BMF 1996;312:34.

10 Sporik R, Holgate ST, Platts-Mills TAE, Cogswell JJ. Exposure to house-dust mite allergen (Der $p \mathrm{I})$ and the development of asthma in childhood. N Engl F Med 1990; 323:502-7.
11 Peat JK. The rising trend in allergic illness: which environmental factors are important? Clin Exp Allergy 1994 24:797-800.

12 Strachan DP, Carey IM. Home environment and severe asthma in adolescence: a population based case-contro study. BMf 1995;311:1053-6.

13 Strachan D, Carey IM. Reduced risk of wheezing in children using feather pillows is confirmed. BMF 1997;314:518.

14 Anderson HR, Butland BK, Strachan DP. Trends in prevalence and severity of childhood asthma. BMF 1994;308: $1600-4$.

15 SAS Institute Inc. SAS/STAT user's guide. Version 6, 4th edition. Cary, North Carolina: SAS Institute Inc, 1989.

16 Breslow NE, Day NE. Statistical methods in cancer research Volume 1: The analysis of case-control studies. Lyon: IARC Volume 1: The analysis of case-control

17 Hasselblad V, Eddy DM, Kotchmar DJ. Synthesis of environmental evidence: nitrogen dioxide epidemiology studies. F Air Waste Manag Assoc 1992;42:662-71.

18 Department of Health. Advisory Group on the Medica Aspects of Air Pollution Episodes. Third report. Oxides of nitrogen. London: HMSO, 1993.

19 Ponce de Leon A, Anderson HR, Bland JM, Strachan DP, Bower J. Effects of air pollution on daily hospital admissions for respiratory disease in London between 1987-88 to 1991-92. F Epidemiol Community Health 1996, 50(Suppl 1):S63-70.

20 Infante-Rivard C. Childhood asthma and indoor environmental risk factors. Am f Epidemiol 1993;137:834-44.

21 Dekker C, Dales R, Bartlett S, Brunekreef B, Zwanenburg $\mathrm{H}$. Childhood asthma and the indoor environment. Chest 1991;100:922-6.

22 Lewis S, Richards D, Bynner J, Butler N, Britton J. Prospective study of risk factors for early and persistent spective study of risk factors for early and persiste

23 Søyseth V, Kongerud J, Boe J. Postnatal maternal smoking increases the prevalence of asthma but not of bronchial increases the prevalence of asthma but not of bronchial hyperresponsive

24 Gold DR, Rotnitzky A, Damokosh AI, Ware JH, Speizer $\mathrm{FE}$, Ferris BG Jr, et al. Race and gender differences in respiratory illness prevalence and their relationship to environmental exposures in children 7 to 14 years of age. Am Rev Respir Dis 1993;148:10-18.

25 Frischer T, Kuehr J, Meinert R, Karmaus W, Barth R Hermann-Kunz E, et al. Maternal smoking in early childhood: a risk factor for bronchial responsiveness to exercise in primary-school children. F Pediatr 1992;121:17-22.

26 Martinez FD, Antognoni G, Macri F, Bonci E, Midulla F, De Castro G, et al. Parental smoking enhances bronchial responsiveness in nine-year-old children. Am Rev Respir Dis 1988;138:518-23.

27 Department of Health. Committee on the Medical Effects of Air Pollutants. Asthma and outdoor air pollution. London: HMSO, 1995: 101-2.

28 Strachan DP, Anderson HR, Limb ES, O`Neill A, Wells N. A national survey of asthma prevalence, severity and treatment in Great Britain. Arch Dis Child 1994;70:174-8.

29 Burr ML, Miskelly FG, Butland BK, Merrett TG, VaughanWilliams E. Environmental factors and symptoms in infants at high risk of allergy. I Epidemiol Community Health 1989;43:125-32.

30 Brunekreef B, Groot B, Hoek G. Pets, allergy and respiratory symptoms in children. Int 7 Epidemiol 1992;21:338-42.

31 Arshad SH. Pets and atopic disorders in infancy. Br f Clin Pract 1991;45:88-9.

32 Clifford RD, Radford M, Howell JB, Holgate ST. Prevalence of respiratory symptoms among 7 and 11 year old schoolchildren and association with asthma. Arch Dis Child 1989; 64:1118-25.

33 Linna O. Environmental and social influences on skin test results in children. Allergy 1983;38:513-6.

34 Popp W, Rauscher H, Sertl K, Wanke T, Zwick H. Risk factors for sensitisation to furred pets. Allergy 1990;45: $75-9$

35 Kuehr J, Frischer T, Karmaus W, Meinert R, Barth R, Herrmann-Kunz E, et al. Early childhood risk factors for sensitisation at school age. 7 Allergy Clin Immunol 1992, 90:358-63.

36 Kemp TJ, Siebers RW, Fishwick D, O’Grady GB, Fitzharri $P$, Crane J. House dust mite allergen in pillows. $B M F$ 1996;313:916. 